\title{
The calculation, design and optimization of sandwich panels using author's programs of the automated designing of development
}

\author{
Stanislav Petrov ${ }^{1}$, Irina Kuznetsova ${ }^{1, *}$, Yuri Doladov ${ }^{1}$ and Nikita Krasnov ${ }^{1}$ \\ ${ }^{1}$ Samara State Technical University, Academy of Architecture and Civil Engineering, \\ Molodogvardeyskaya St., 194, Samara, 443001, Russia
}

\begin{abstract}
Three-layer sandwich panels are widely used in insulation of walls and roofing of buildings and other various structures. At the moment building products markets are full of various types of panels by produced different manufactures but skinned with one and the same material only. Panels skinned with two different types of materials are widely used in the sphere of transport. It may be also of considerable economical effect in building engineering. The article presents an analysis of the current state of the problem of calculation of thin-walled profiles in load-bearing structures. The authors developed a program of automated calculation of three-layer panels. The program is certified in Russia. The program allows you to optimize the panel parameters according to the cost criterion. The article presents the basic calculation ideas incorporated in the algorithm of the program. The figures show the program interface. To date, the program has only one Russian language interface. The paper introduces automated methods of single- and multi-span sandwich panels trial design. Different types of materials can be used while skinning these panels. Their middlelayer shift and compliance of supporting structures are taken into account.
\end{abstract}

\section{Introduction}

Thin-walled metal structures are widely used as bearing structures of buildings and structures [1-18]. Three-layer sandwich panels are widely used in insulation of walls and roofing of buildings and other various structures.

These panels consist of two rigid sheathings glued to a comparatively light middle layer. The cross section of a panel sheathing depends on its function and span. Thus, the cross section can be flat or profiled. The sheathings can be made of metal (thin sheet steel or aluminum) or composites materials (laminated particle board, construction veneer or fiberglass). The main characteristic feature of these structures is their middle layer shearing capacity. Their middle layer can be made of separate mineral-cotton bars, which have been cut and stabbed together. It can as well be made of expanded foam blown between panel sheathings.

\footnotetext{
Corresponding author: avu75@mail.ru
} 
At the moment building products markets are full of various types of panels by produced different manufactures but skinned with one and the same material only. Panels skinned with two different types of materials are widely used in the sphere of transport. It may be also of considerable economical effect in building engineering.

The increasing volume of use of thin-walled profiles in construction gave rise to the development of programs for automated calculation of such structures [19, 20].

\section{Materials and methods}

The most calculation methodologies $[21,22]$ take into account neither supporting structures general lay-out and rigidity nor external load actions or the number of spans. A. Levtchuk [23], in his turn, insists that the difference in position of panels tops should be necessarily taken into account while using multi-span sandwich panels. It means that we should also consider multi-span panels supporting structures flexibility while designing such panels.

To make calculation process automatic the authors work out an $\mathrm{C}++$ algorithm using KiSP Program [29]. This algorithm makes it possible to calculate stress and strain state of threelayer sandwich panels with account of middle-layer shift and elastic compliance of supporting structures. This calculation does not depend on either evenly distributed loads or trapezoidal shear loads. The algorithm also considers nonlinear nature of the construction which, in its turn, comes from vertical supporting structures flexibility coefficient and its dependence of corresponding support resistance.

To work out the algorithm for KiSP Program the researches used the three-layer sandwich panels calculation methodology with account of middle-layer shift and supporting structures flexibility, firstly introduced in Papers [24, 25]. KiSP Program makes it possible to perform static analysis of the panel for combined effect of any static shear load and temperature impact (that is with sharp variations in temperature between sheets of the panel). This methodology is based on A. Rzhanitsin's theory of compound bars [26]. This methodology makes use of advanced calculation model (developed with the help of inplace tests $[27,28]$ ). In this model supporting structures reactions on the panel go through grounds of finite width.

The basic data for calculations with the use of KiSP program are characteristics of a panel different elements cross-sections, this panel spans size, cross-section and span of beams of the panel, construction loads (Figure 1).

As results of sandwich panels calculations, the program in question shows graphical and tabulated data including supporting structures reactions, panel elastic line motion, internal force curves, the stress and strain state of the panel sheets and middle layer (Figure 2).

KiSP program helps automatize calculations and produce three-layer sandwich panels trial design while varying the construction parameters.

The modern level of development of methods of calculation of building structures allows the use of advanced methods of optimal design [30-32].

To develop three-layer panels optimal and trial design we take the construction field adjusted parameters cost [33] as the general target function of the model:

$$
C=C_{\text {mat }}+C_{\text {manuf }}+C_{t}+C_{a}=\min
$$

where $C_{\text {mat }}, C_{\text {manuf }}, C_{t}, C_{a}$ - is panels materials and manufacture cost, as well their transportation and assembling cost. 

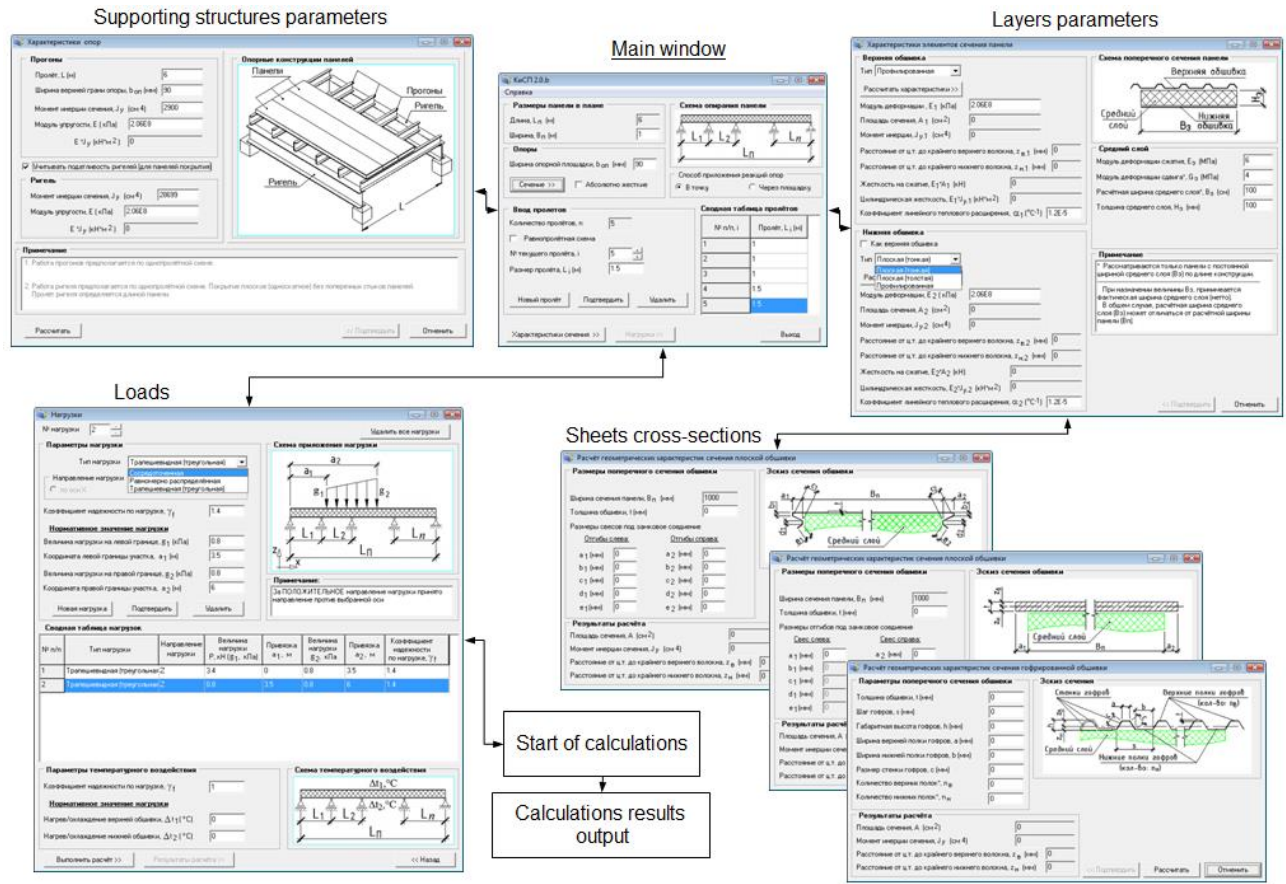

Fig. 1. KiSP program dialogue boxes.

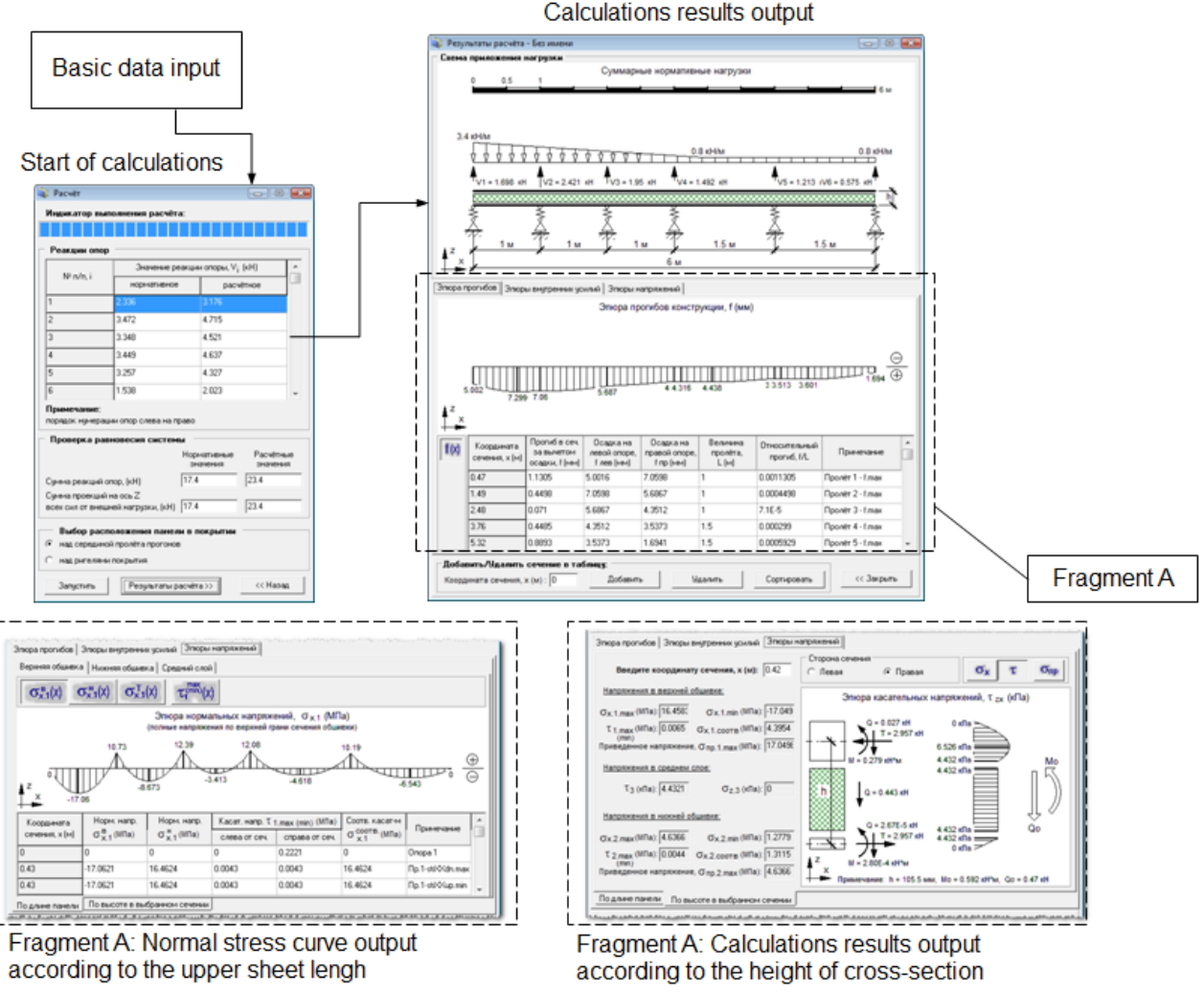

Fig. 2. KiSP program data calculations window. 
In case we take the same parameters of the materials used and the same structural diagram, the first three components can slightly vary (when compared with the fourth). So, we believe that the economical effect mostly depends on the cost of sheets materials and the cost of insulates. Thus, the target function is:

$$
C_{M}=C_{\text {upper }}+C_{\text {lower }}+C_{\text {middle }}=\min
$$

where $C_{\text {upper }}, C_{\text {lower }}, C_{\text {middle }}$ determine the cost of upper and lower sheets and the coos of the middle layer. The cost of each layer depends on its weight mi and the unit cost of materials $\gamma_{i}$ :

$$
C_{i}=m_{i} \cdot \gamma_{i}
$$

where $i$ - layer index ( $i=$ upper sheet, lower sheet, middle layer).

While calculating the target function (2) minimum, one should take the basic data in-to account and accept design and calculation constraints.

The basic data here are as follows: physical mechanical properties of the layers materials, the size of the panel as for the number of spans in it, the application of loads scheme (both force and temperature impact) and load intensity, supporting structures parameters (cross-section, span, physical mechanical properties of material used).

To design constraints we refer discreteness of sheets and insulant gauge material, discreteness of sheets material corrugation, discreteness of the span between the panel supporting structures, middle layer minimum thickness necessary for heat transmission resistance.

To calculation constraints we refer conditions of deformation compatibility with account of middle-layer shift and supporting structures squeeze reduction, conditions of the whole construction rigidity, conditions of all layers materials strength, conditions of squeezed sheets resistance, conditions of layer interconnections strength and durability.

\section{Conclusions}

The basis for the general optimal and trial design algorithm is a parametric task of reducing the cost of a panel with sheets and middle layer made of definite materials while the calculation scheme and supporting structures rigidity are the same. Using design automation facilities makes the whole process of calculating other optimal tasks easier and quicker.

The solution for the parametric task is achieved while changing discrete parameters of sandwich panels layers. According to customers' requirements different combinations of materials can be used as panels layers.

Sandwich panels trial design methodology and its procedure are schematically shown on Figure 3. 


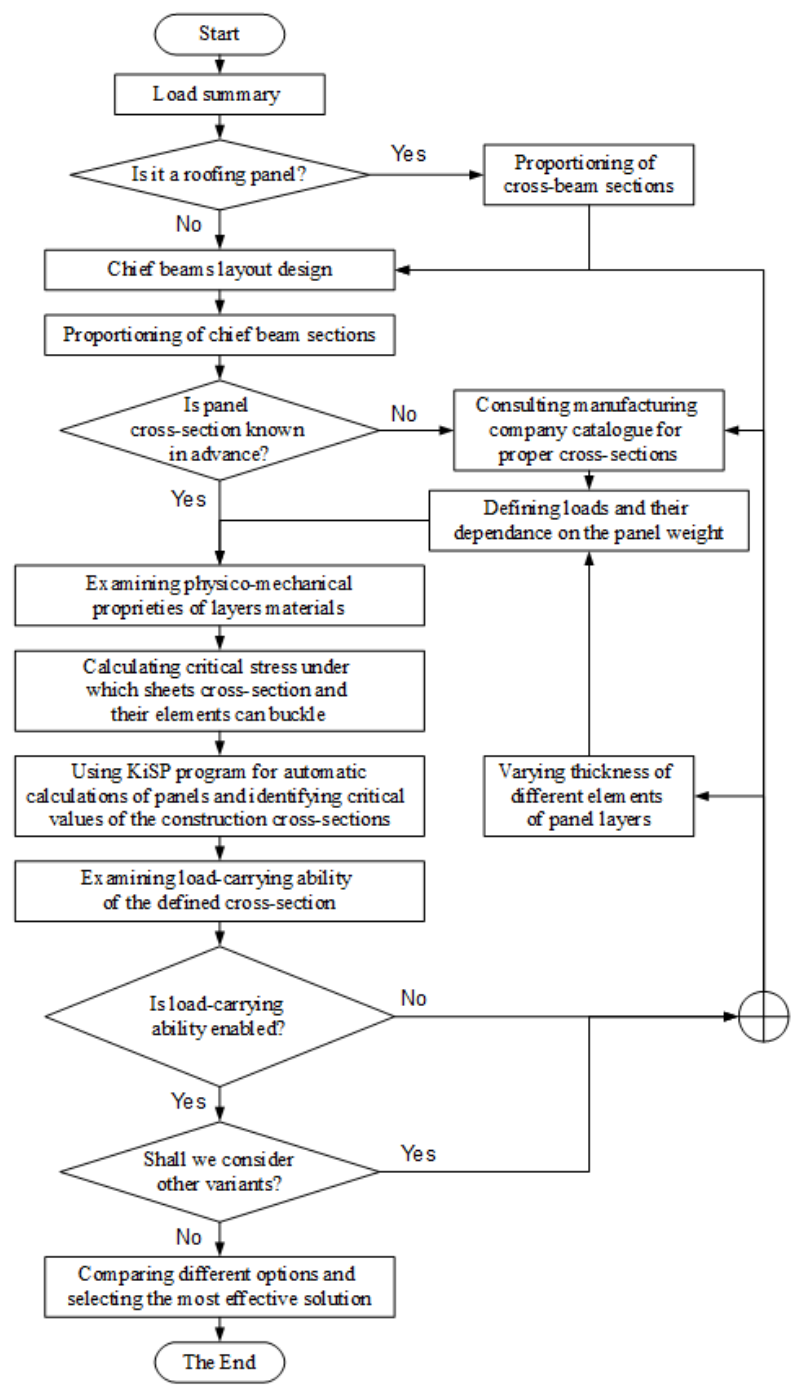

Fig. 3. Sandwich panels trial design methodology and its procedure.

\section{References}

1. V. Alpatov, A. Soloviev, MATEC Web Conferences 196, 01008 (2018)

2. V. Zubkov, A. Lukin, V. Alpatov, MATEC Web Conferences 196, 01005 (2018)

3. A. Lukin, V. Alpatov, Science News of Eastern Technical Universities 3, pp. 38-42 (2016)

4. A. Lukin, V. Alpatov, et al, Construction. New technologies, new equipment 9, pp. 5255 (2106)

5. A. Lukin, I. Kholopov, et al, Procedia Engineering 153, pp. 414-418 (2016)

6. A. Lukin, V. Alpatov, et al, Bulletin of SSAU. Urban planning and architecture 2, pp. 4-9 (2016) 
7. M. Balzannikov, I. Kholopov, et al, Procedia Engineering 11, pp. $72-81$ (2015)

8. I. S. Kholopov, V. Yu. Alpatov, A. V. Atamanchuk, Building materials, equipment, technologies of XXI century 1, 66-68 (2008)

9. I. S. Kholopov, V. Yu. Alpatov, A. V. Solovyev, Science and education in the XXI century. Collection of scientific papers based on materials of the International Scientific-Practical Conference: in 34 parts, 145-147 (2013)

10. I. S. Kholopov, V. Yu. Alpatov, et al., Collection of reports of the scientific and practical conference dedicated to the 100 anniversary of Professor E. I. Beleny "Calculation and design of metal structures", 236-241 (2013)

11. A. Soloviev, A. Lukin, V. Alpatov, Industrial and civil construction 6, pp. 27-30 (2010)

12. V. Alpatov, I. Kholopov, Patent for utility model RUS 31252 (2003)

13. V. Alpatov, Patent for utility model RUS 111172 (2011)

14. I. Kholopov, A. Lukin, V. Alpatov, Patent for utility model RUS 153248 (2015)

15. I. Kholopov, A. Lukin, et al., Patent for utility model RUS 158932 (2016)

16. A. Lukin, et al., Patent RUS 2629270 (2017)

17. A. Lukin, et al., Patent for utility model RUS 166510 (2016)

18. A. Lukin, et al., Patent for utility model RUS 160142 (2016)

19. M. Khlystunov, I. Kholopov, et al., Certificate of software registration RUS 2012661038 (2013)

20. A. Lukin, A. Suvorov, et al., Certificate of software registration RUS 2018611590 (2018)

21. TSNIISK named for V.A. Kucherenko. Calculating three-layer panels with metal skin and expanded foam aggregate (Moscow: Stroyizdat, 1976)

22. EN 14509:2005 (E): Self-supporting double skin metal faced insulating panels. Factory made products. Specifications. Final draft (European Committee for Standardisation, 2006)

23. A.A. Levchuk, Modern metal and timber building structures. Scientific Proceedings 1, pp. 179-184 (2008)

24. S.M. Petrov, Building Mechanics and Structures Calculation 4, pp. 27-33 (2010)

25. S.M. Petrov, Building Mechanics and Structures Calculation 1, pp. 23-28 (2013)

26. A.R. Rzhanitsin, Compound bars and plates (Moscow: Stroyizdat) (1986)

27. I.S. Kholopov, M.D. Mosesov, et al, Higher education establishments news. Building Engineering 2, pp. 108-112 (2008)

28. S.M. Petrov, E.V. Ildiyarov, et al, Industrial and civil engineering 6, pp. 44-47 (2009)

29. S.M. Petrov, KiSP Program. Certificate of software registration RUS 2012614613 (2009)

30. V. Alpatov, MATEC Web Conferences 117, 00007 (2017)

31. V. Yu. Alpatov, A. A. Sakharov, et al, MATEC Web Conferences 86, 02021 (2016)

32. V. Yu. Alpatov, A.O. Lukin, et al, Procedia Engineering 111, pp. 20-29 (2015)

33. Ya.M. Likhtarnikov, Building structures trial design and optimization (Moscow: Stroyizdat) (1976) 